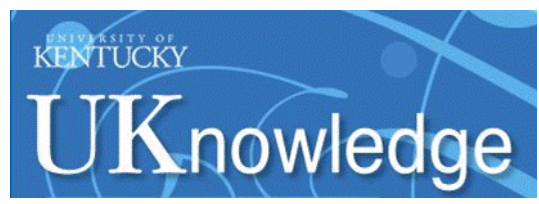

University of Kentucky

UKnowledge

\title{
Reducing Cancer Disparities through Community Engagement in Policy Development: The Role of Cancer Councils
}

\author{
Michael A. Preston \\ University of Arkansas, prestonm2@vcu.edu \\ Glen P. Mays \\ University of Kentucky, glen.mays@cuanschutz.edu \\ Rise' D. Jones \\ University of Illinois \\ Sharla A. Smith \\ University of Arkansas \\ Chara N. Stewart \\ St. Jude Hospital
}

See next page for additional authors

Follow this and additional works at: https://uknowledge.uky.edu/hsm_facpub

Part of the Health Services Administration Commons, and the Health Services Research Commons Right click to open a feedback form in a new tab to let us know how this document benefits you.

\section{Repository Citation}

Preston, Michael A.; Mays, Glen P.; Jones, Rise' D.; Smith, Sharla A.; Stewart, Chara N.; and Henry-Tillman, Ronda, "Reducing Cancer Disparities through Community Engagement in Policy Development: The Role of Cancer Councils" (2014). Health Management and Policy Faculty Publications. 6.

https://uknowledge.uky.edu/hsm_facpub/6

This Article is brought to you for free and open access by the Health Management and Policy at UKnowledge. It has been accepted for inclusion in Health Management and Policy Faculty Publications by an authorized administrator of UKnowledge. For more information, please contact UKnowledge@lsv.uky.edu. 


\section{Reducing Cancer Disparities through Community Engagement in Policy Development: The Role of Cancer Councils}

Digital Object Identifier (DOI)

http://dx.doi.org/10.1353/hpu.2014.0069

Notes/Citation Information

Published in Journal of Health Care for the Poor and Underserved, v. 25, no. 1, p. 139-150.

Copyright @ 2014 The Johns Hopkins University Press. This article first appeared in Journal of Health Care for the Poor and Underserved, Volume 25, Issue 1, February, 2014, pages 139-150.

\section{Authors}

Michael A. Preston, Glen P. Mays, Rise' D. Jones, Sharla A. Smith, Chara N. Stewart, and Ronda HenryTillman 


\title{
Reducing Cancer Disparities through Community Engagement in Policy Development: The Role of Cancer Councils
}

\author{
Michael A. Preston, PhD, MPH \\ Glen P. Mays PhD, MPH \\ Rise' D. Jones, $\mathrm{PhD}$ \\ Sharla A. Smith, PhD, MPH \\ Chara N. Stewart, MPH \\ Ronda S. Henry-Tillman, MD, FACS
}

\begin{abstract}
Cancer is the second leading cause of death in the U.S and a source of large racial and ethnic disparities in population health. Policy development is a powerful but sometimes overlooked public health tool for reducing cancer burden and disparities. Along with other partners in the public health system, community-based organizations such as local cancer councils can play valuable roles in developing policies that are responsive to community needs and in mobilizing resources to support policy adoption and implementation. This paper examines the current and potential roles played by local cancer councils to reduce cancer burden and disparities. Responsive public health systems require vehicles for communities to engage in policy development. Cancer councils provide promising models of engagement. Untapped opportunities exist for enhancing policy development through cancer councils, such as expanding targets of engagement to include private-sector stakeholders and expanding methods of engagement utilizing the Affordable Care Act's Prevention and Public Health Fund.
\end{abstract}

Key words: Cancer disparities, community engagement, health care reform, policy.

\footnotetext{
ancer is the second leading cause of death in the U.S and a source of large racial and ethnic disparities in population health. ${ }^{1,2}$ The causes of cancer disparities is multifactorial and arise from socioeconomic factors such as poverty, lack of health insurance, inadequate education, housing, and overall standard of living, as well as social barriers to high-quality cancer prevention, early detection, and treatment ser-

DR. PRESTON is affiliated with the University of Arkansas for Medical Sciences (Winthrop P. Rockefeller Cancer Institute) in Little Rock, Arkansas. DR. MAYS is affiliated with the University of Kentucky (Public Health Services and Systems Research National Coordinating Center). DR. JONES is affiliated with the University of Illinois. DR. SMITH is affiliated with Health Policy and Management at the University of Arkansas for Medical Sciences. MS. STEWART is affiliated with St. Jude Hospital. DR. HENRY-TILLMAN is affiliated with the Winthrop P. Rockefeller Cancer Institute and the University of Arkansas for Medical Sciences. Please address correspondence to Dr. Michael Preston at University of Arkansas for Medical Sciences, Cancer Control, 4301 W. Markham St., \#827, Little Rock, AR 72205; (501) 526-7101; mapreston@uams.edu.
} 
vices. ${ }^{1}$ For more than 10 years, the nation has been committed to eliminating cancer disparities. ${ }^{3}$ The elimination of cancer disparities is defined by previous literature as "a reduction in cancer incidence and mortality and an increase in cancer survival among socioeconomically disadvantage people to levels comparable to those in the general population."3 The elimination of cancer disparities has become a national priority of both the public and private sectors. ${ }^{3}$

Cancer disparities are viewed as a public health issue that health care reform can address with enhanced funding of health education programs at the community level. . $^{4-6}$ The elimination of cancer-related disparities is one of the American Cancer Society's (ACS) 2015 challenge goals toward addressing disparities as a public health issue. ${ }^{3}$ The Affordable Care Act (ACA) of 2010 created the Prevention and Public Health Fund with a focus on public health and disease prevention. This Fund was established to expand evidence-based interventions that involve community-based organizations. The ACA offers a solid foundation for addressing health disparities at the community level. Strategies that focus on public health at the community level can ensure coordination of prevention activities based on a community's health needs and priorities. The goal of reducing cancer disparities is ambitious and may only be reached by the collective resources of state, federal, community organizations and private health organizations. Community engagement has been identified as one strategy for effectively mobilizing collective resources and directing it to meet the needs associated with cancer disparities at the local level.

Community engagement is an intervention welcomed by community leaders, policymakers, and funders engaged in health-related activities. Community-based organizations (CBOs) are a popular choice for addressing public health problems in communities where other kinds of approaches have failed. ${ }^{7-16}$ Community-based organizations are being recognized as a key mechanism for intervention-related activities from smoking to teen pregnancy to underage drinking and driving to cancer prevention and screening. ${ }^{17,18}$ In its 2002 report, The Future of the Public's Health, the Institute of Medicine recommended governmental public health agencies provide direct support for community health-improvement initiatives by assessing community needs, providing technical assistance, and developing solutions that improve health status. In spite of such efforts, cancer continues to plague underserved communities-particularly minority communities - and create enormous health disparities between them and the majority. ${ }^{19-28}$

Like community engagement, policy (at the state, local and federal levels) is a tool for improving health. ${ }^{17}$ Policy development is a powerful but sometimes overlooked public health tool for reducing cancer burden and disparities. Along with other partners in the public health system, community-based organizations can play valuable roles in developing policies that are responsive to community needs and in mobilizing resources to support policy adoption and implementation. In Arkansas, Act 2236, The Colorectal Cancer Act of 2005, was established as a result of such collaborative efforts. ${ }^{29-31}$ Local cancer councils are community-based organizations based on voluntary partnerships formed by community organizations to pursue common interests in policy development to reduce cancer burden and disparities. The use of local cancer councils is essential because such community organizations are close to the populations they serve and are 
therefore a crucial part of the public health system for identifying needs and responses and evaluating results. ${ }^{32}$ To examine the current and potential roles played by local cancer councils, we collected information from members of these community-based organizations.

\section{Methods}

A descriptive and formative study utilizing a self-administered survey instrument collected information from members of local cancer councils operating in six rural Arkansas counties. The mixed-method survey was designed and tested prior to study initiation. Information included members' current and past experience in cancer policy development, types of policy issues addressed, array of policy decision-makers with whom council members interact, and types of methods used to inform policy discussions along with the extent and nature of variation in these methods across communities.

The infrastructure for expanding community outreach programs and evidence-based interventions was provided as a result of the Arkansas Cancer Community Network (AR-CCN). The goal of this network was to increase knowledge, access, beneficial and sustainable programs to reduce cancer disparities in Arkansas. To provide a tool for communication with various communities in the network, eCOPT was developed as a web-based program to improve health education. eCOPT was used by the network not as a replacement, but as a support for and supplement to face-to-face meetings, phone conversations, teleconferences, questionnaires/surveys, and other personal contacts. The survey was administered at regularly scheduled cancer council meetings using the web-based program called eCOPT, which allows members to use the self-administered assessment tool. The local cancer councils are community-based organizations in Arkansas that participate in AR-CCN.

Cancer councils serve as the primary mechanism through which the AR-CCN develops and implements integrated interventions, community training programs, and research projects. These groups provide community leadership to address cancer education and cancer health disparities within their respective communities, thus linking AR-CCN with communities. As liaisons, local cancer councils engage their communities in cancer awareness events and coordinate activities among various health service organizations to provide preventive breast, prostate, cervical, and colorectal cancer screening and education. These councils work with academic investigators to identify cancer disparities and develop research interventions to address these priority areas. These cancer councils were supported by the Roy and Christine Sturgis Charitable and Educational Trust Foundation. To facilitate communication among cancer councils and to bring the voice of each participating community to the AR-CCN Steering Committee, a cancer council member from each council, county, and the AR-CCN Community Advisory Board (CAB) served on this committee.

Population and study design. Participants from six community-based organizations called cancer councils received the questionnaire between January and July 2009. A primary contact for each cancer council received an e-mail message from Arkansas Cancer Community Network staff containing a link to the questionnaire. Each cancer council had 10-15 members and each member was asked to participate in the study. 
These members provided descriptive data that allowed the researchers to determine their level of engagement in policy development activities to reduce cancer burden and disparities. All cancer council members were eligible for inclusion. Additionally, members of the AR-CCN Community Advisory Board were asked to participate in the survey since this board governs the activities of the local cancer councils; the Advisory Board comprises 12 Arkansas residents appointed by an affiliated university to provide guidance and advice to the AR-CCN project. Members of this board include civic, faith-based, and public health leaders from across the state who share an interest in reducing cancer disparities.

Data collection. Surveys were completed at regularly scheduled cancer council meetings. Each self-administered survey was completed in approximately 30 minutes. The survey instrument was completed electronically through a secure website maintained by the University of Arkansas for Medical Sciences (UAMS), using any computer with an Internet connection and web browser. At any point in the survey, subjects were allowed to stop their participation to continue at a later point in time. Responses to the questionnaire were transmitted via the Internet to a database server maintained by UAMS investigators, using encryption methods that prevented others from viewing participant responses. All information obtained through the questionnaire that could be identified with a subject or their community cancer council remained confidential and will be disclosed only with the subject's permission or as required by law. No individual identifying information (such as subject name, address, or contact information) was collected through the survey. The only geographic information collected through the survey was an indicator for the cancer council to which the participant belonged.

Data analysis. After all surveys were completed, the data were extracted from eCOPT and were used for a descriptive analysis to identify the types of policy development activities that cancer council members participate in, the types of policy issues that members address, and their perceived strengths and weaknesses in informing and influencing local health policy decisions. SAS 9.1 was used to conduct our analysis.

The findings from this analysis document the roles currently played by local cancer councils in public health policy development, along with the extent and nature of variation in these roles across communities. Opportunities for expanding and enhancing the policy development activities of cancer councils were examined.

\section{Results}

A self-administered survey of cancer council's members ( $\mathrm{n}=77 ; 86 \%$ response rate) was used to assess their current and past experiences in cancer policy development, types of policy issues addressed, types of policy decision-makers with whom they interact, and types of methods used to inform policy discussions.

Most members of the six community cancer councils in Arkansas are from the Arkansas Department of Health (27.6\%) and community-based organizations (39.8\%). Cancer council members also include elected or appointed officials of state or local government (6.1\%), churches or other faith-based organizations $(9.2 \%)$, health care professionals (6.1\%), hospitals or health care organizations (6.1\%), and business owners and/or members of the local Chamber of Commerce (5.1\%). 


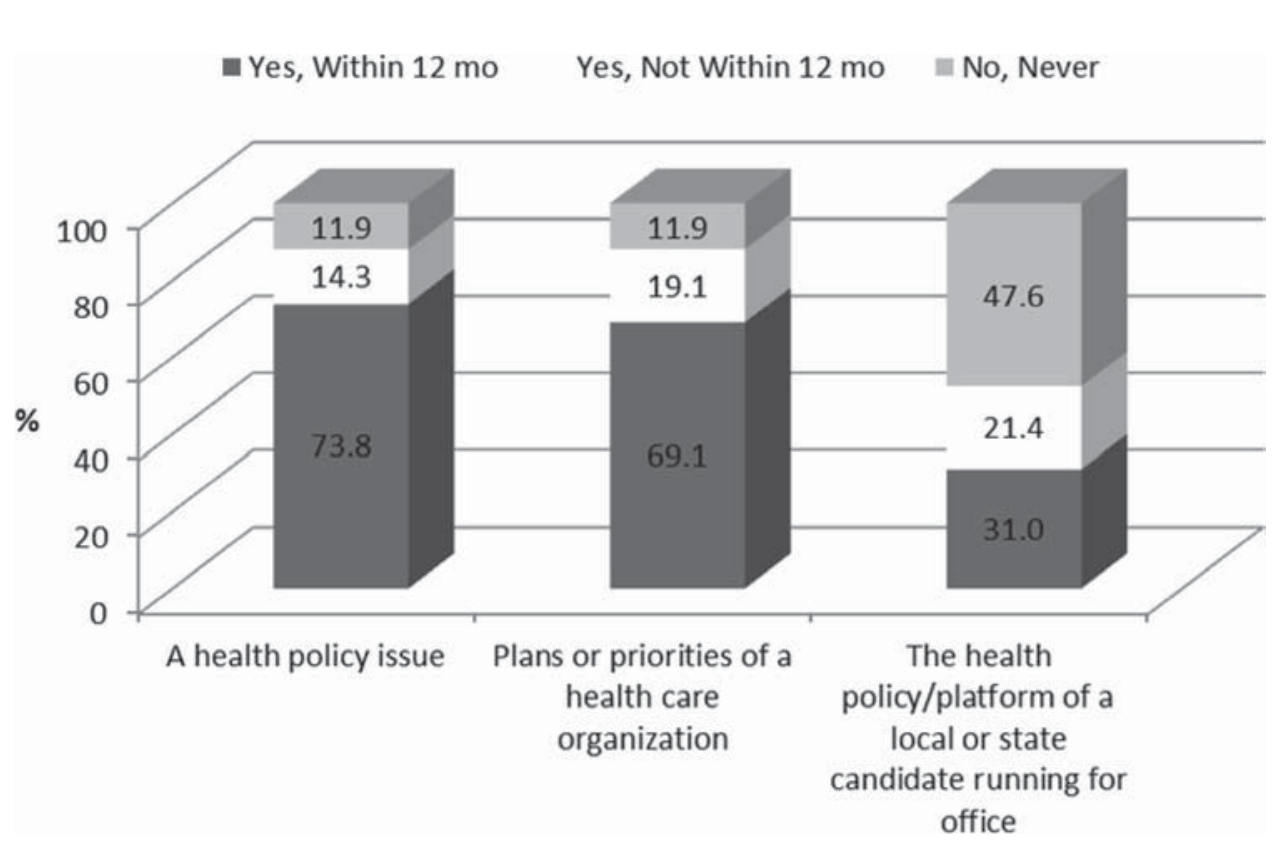

Figure 1. Experience in policy development discussions $(n=77)$.

Awareness of and exposure to health policy issues were high among council members, with $88 \%$ reporting experience in policy development activities. Figure 1 represents the member's experience in policy discussions. Among the members with such experience, $81 \%$ discussed cancer prevention and screening. Through their attendance of meetings to learn about the plans or priorities of health care organizations that serve their respective communities, $88 \%$ of respondents had some level of experience in policy development discussions. Among the members with such experience, $76.9 \%$ discussed cancer prevention and screening. Finally, only $52 \%$ of participants have experience in policy development discussions while attending meetings to learn about the health policies or platform of a local or state candidate running for office. Among the members with such experience, $78.3 \%$ discussed cancer prevention and screening.

Of all the participant experiences in policy development discussions, the most influential interactions with policy stakeholders were those associated with prominent area employers (68\%), a church or religiously-affiliated decision-making body (75\%), and the Arkansas Department of Health (82\%). The fewest interactions took place among the local Medical Society (21.1\%), local Chamber of Commerce (46.6\%), local or regional Health Board/Hospital Boards (48.5\%), and Community Center Administrators or Leaders (40.6\%). Figure 2 presents the interaction with policy stakeholders. These findings suggest that members are not interacting with policy stakeholders who have the most influence on policies.

Results of the survey include the following: interactions with policy- and decisionmakers during the past 12 months resulted in addressing health policy issues related to cancer prevention and screening (13.1\%), tobacco policy (12.7\%), and health disparities and health issues $(10.0 \%)$. The health policy issues least often discussed during this 


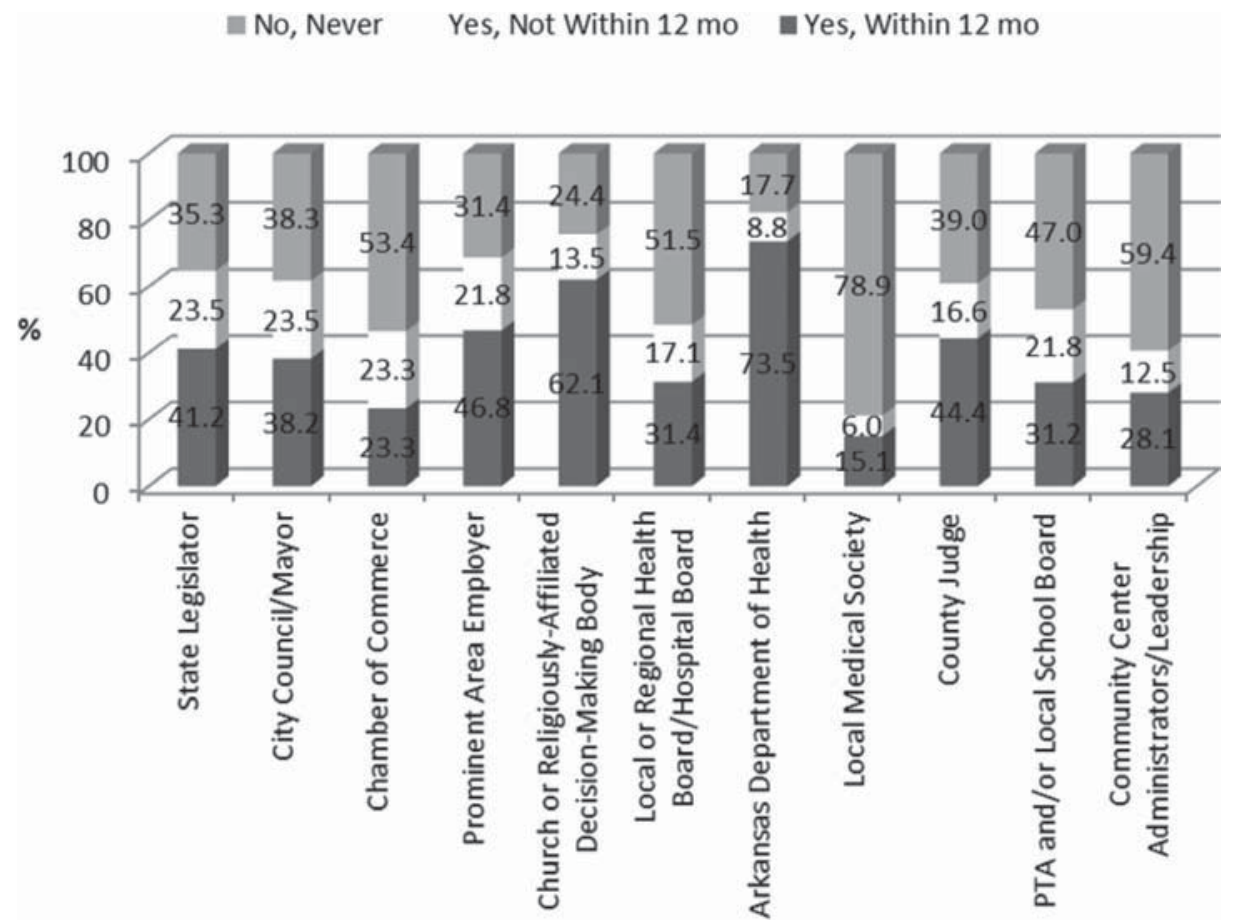

Figure 2. Interaction with policy stakeholders $(\mathrm{n}=77)$.

period were survivorship issues (3.9\%), cancer treatment (5.7\%), and environmental health concerns (5.7\%).

The methods that participants most commonly reported using to inform policy discussions were voting $(67.5 \%)$ and contacting a public officials $(67.5 \%)$ with perceived effectiveness of $91.6 \%$ and $92.3 \%$, respectively (see figure 3 ). The method least frequently reported being used to inform policy discussions were protesting (7.5\%) and canvassing (15.0\%). Although few cancer council members reported informing policy discussions by protesting and canvassing, everuyone who uses these methods considers them to be highly effective.

Policy self-efficacy was high among participants (see Figure 4). Eighty-five percent of participants reported having the knowledge necessary to talk with a local official about a health issue, and $73.2 \%$ of respondents indicated they have the skills to support their interest in changing a health care issue. In spite of the high sense of self-efficacy, only $41.5 \%$ believe that there are available resources to support their interest in providing a change in health care.

Finally, we assessed participants perceived needs for technical assistant. Figure 5 presents the perceived technical assistance needs of council members. The most commonly reported need was being able to identify the correct person in order to address a policy concern $(22.5 \%)$. Speaking with the media on health policy topics $(12.7 \%)$ and understanding the policymaking process at the local level (14.1\%) were reported by the fewest participants. 


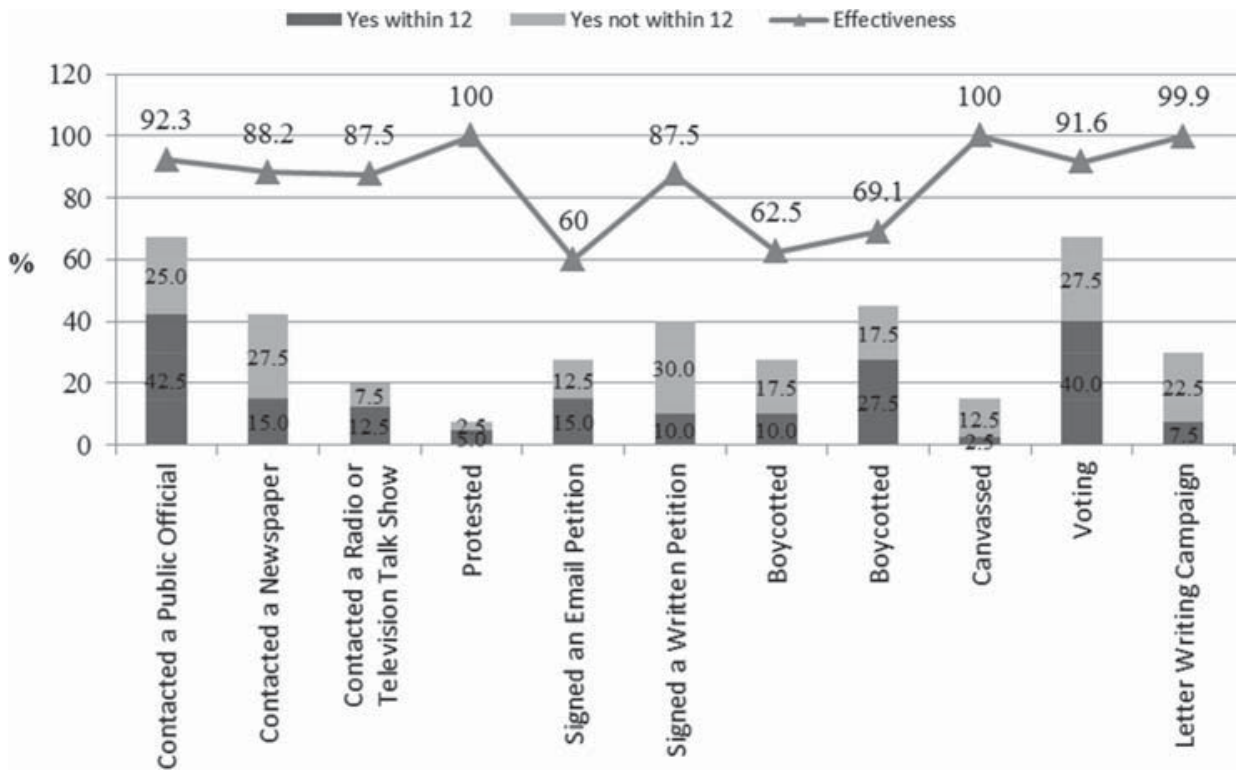

Figure 3. Types of methods used to inform policy discussions $(n=77)$.

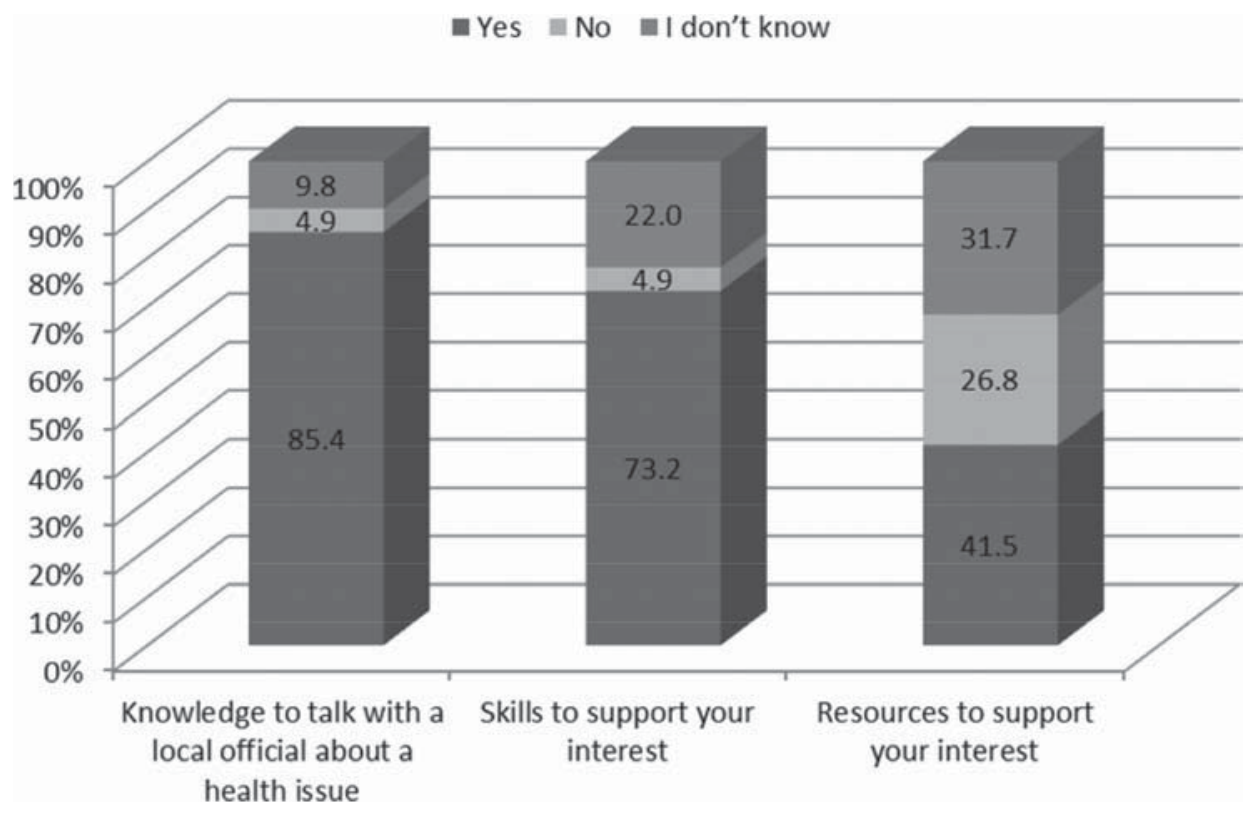

Figure 4. Perceived self-efficacy in policy development $(n=77)$. 


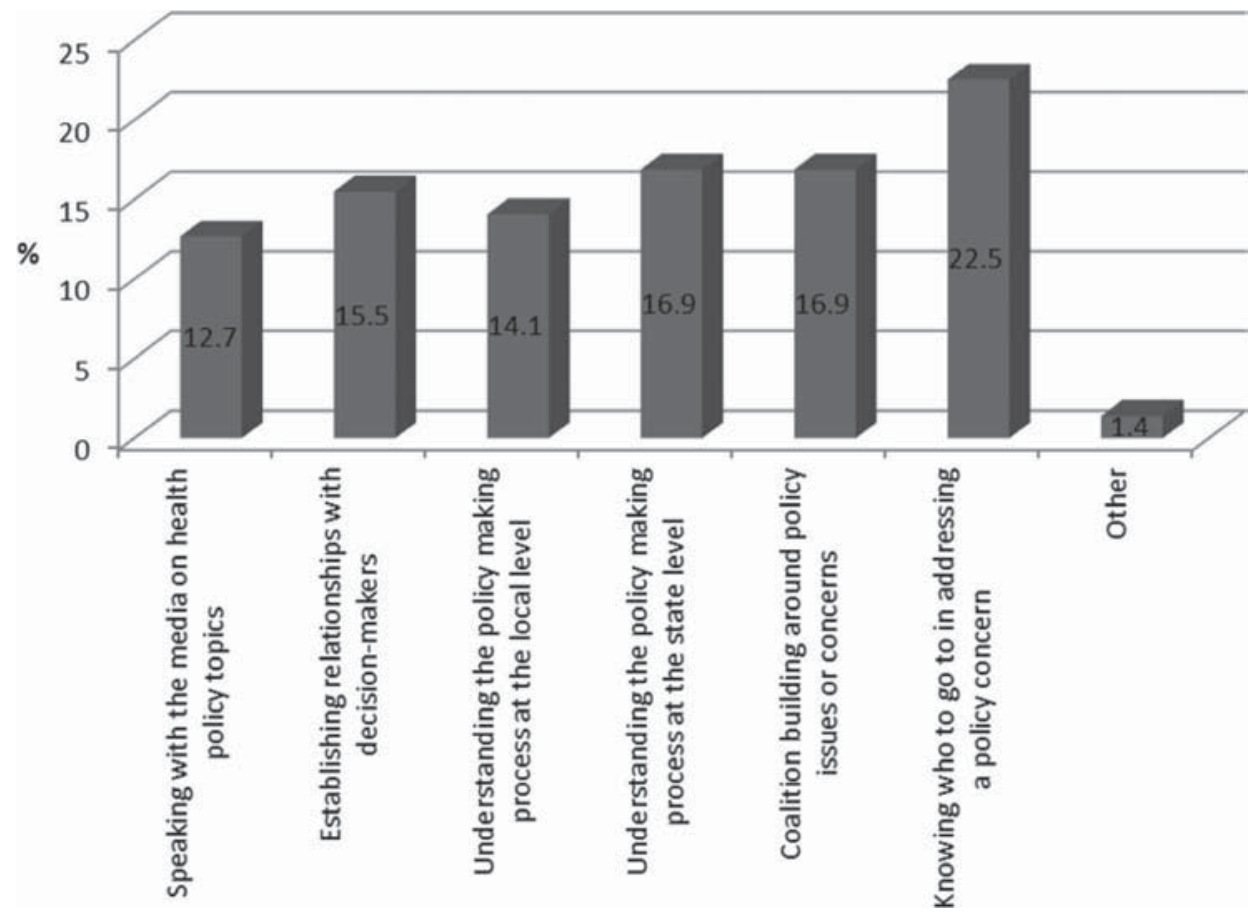

Figure 5. Perceived technical assistance needs $(\mathrm{n}=77)$.

\section{Discussion}

The Affordable Care Act established the Prevention and Public Health Fund to provide expanded and sustained national investments in prevention and public health, to improve health outcomes, and to enhance health care quality. As a result, the Fund has provided an expansive number of activities to include evidence-based interventions that involve community-based organizations. The Prevention and Public Health Fund is also responsible for establishing through the Center for Disease Control and Prevention the Community Transformation Grants that support community-level efforts to reduce chronic diseases such as heart disease, cancer, stroke, and diabetes.

Health care reform has provided a platform to address health disparities at the community level. With this platform, it is important that we provide ways to engage communities. Engaging the community in activities that have the greatest impact requires resources. ${ }^{26}$ This survey results reported here has demonstrate that although participants' self-efficacy was high, few believed that their community had the necessary resources to carry-out policy development activities. The Prevention and Public Health Fund can be a valuable asset to communities that seek to reduce the burden of chronic diseases and disparities using policy development activities. Funding could be used to promote health education related to a specific health problem that is relevant to their community, establish a community-based organization if needed, and/or maintain a community-based organization (such as a local cancer council).

Communities with cancer councils that are more engaged in some level of policy 
development have increased potential to influence the overall health of their community. ${ }^{17,33}$ Future studies should examine the most influential interactions with policy stakeholders that can make changes to policies. Policy development should be driven by interactions among cancer council members and influential stakeholders such as the Local Medical Society, Chamber of Commerce, Local or Regional Health Board/ Hospital Board, and Community Center Administrators/Leadership..$^{34}$ Based on our findings, it is suggested that members were not interacting with policy stakeholders who have the most influence in making changes to policies. To truly make an impact on health disparities, localpolicy makers must take action and become entrenched with policy development to better their community.

Conclusions. Collectively, these findings suggested ways in which local cancer councils can serve as vehicles for community engagement for the larger public health systems in which they operate. Cancer council members are engaged in frequent policy development opportunities on a variety of cancer policy issues. Their current engagement occurs more often with governmental policy stakeholders than with influential private sector interests such as chamber of commerce, medical society, and hospitals. Findings also provide evidence that cancer council members have high perceived selfefficacy but need resources and technical assistance to support policy development.

Community engagement through local cancer councils may inform and improve the policy development processes within public health systems. Findings may be used to develop interventions to enhance community engagement in policy for the population studied.

The information can help the participants better manage and participate in policy development activities. Knowledge and skills may also contribute to an increase in planning, implementing, and evaluating community health policies.

Implications. Responsive public health systems require vehicles for communities to engage in policy development. Cancer councils provide promising models of engagement. Untapped opportunities exist for enhancing policy development through cancer councils, such as expanding targets of engagement to include private-sector stakeholders and expanding methods of engagement utilizing the Affordable Care Act Prevention and Public Health Fund. The Prevention and Public Health Fund may provide the resources to engage communities in policy development activities effectively.

\section{Acknowledgments}

The work reported in this document was supported by the National Cancer Institute, Arkansas Cancer Community Network (AR-CCN) Grant \# (U01 CA114607). The authors acknowledge the Winthrop P. Rockefeller Cancer Institute Cancer Control Department, Mrs. Kimberlyn Blann-Anderson, Dr. Zoran Bursac, and Dr. Alesia Ferguson for their support and guidance. The authors also acknowledge the participation and support of the Community Cancer Councils, includingthe councils in Bradley County, Cleveland County, Marion County, Mississippi County, Phillips County, and St. Francis County.

Disclosure Statement. The contents of the article are solely the responsibility of the authors and do not necessarily represent the views of the funding agency. 


\section{Notes}

1. American Cancer Society. Cancer facts \& figures 2013. Atlanta, GA: American Cancer Society, 2013.

2. Centers for Disease Control and Prevention. Cancer prevention and control. Atlanta, GA: Centers for Disease Control and Prevention, 2013.

3. Ward E, Jemal A, Cokkinides V, et al. Cancer disparities by race/ethnicity and socioeconomic status. CA Cancer J Clin. 2004 Mar-Apr;54(2):78-93. http://dx.doi.org /10.3322/canjclin.54.2.78; PMid:15061598

4. Olaya W, Wong J, Morgan JW, et al. Factors associated with variance in compliance with a sentinel lymph node dissection quality measure in early-stage breast cancer. Ann Surg Oncol. 2010 Oct;17 Suppl 3:297-302. Epub 2010 Sep 19. http://dx.doi.org /10.1245/s10434-010-1248-0; PMid:20853050

5. Wimbush E, Young I, Robertson G. Developing effective policy and practice for health promotion in Scotland. Promot Educ. 2007;14(4):228-2. http://dx.doi.org/10.1177 /10253823070140040901; PMid:18372874

6. Hagen PC, Nuss DW, Ellis M, et al. Health care crisis: the head and neck cancer patient and affordable health insurance. Ear Nose Throat J. 1993 May;72(5):334-7, 340.; PMid:8334963

7. Harris JR, Brown PK, Coughlin S, et al. The cancer prevention and control research network. Prev Chronic Dis. 2005 Jan;2(1):A21. Epub 2004 Dec 15.; PMid:15670474 PMCid:PMC1323324

8. Kerner JF, Cazap E, Yach D, et al. Comprehensive cancer control-research \& development: knowing what we do and doing what we know. Tumori. 2009 Sep-Oct;95(5): 610-22.; PMid:19999951

9. Kerner JF, Guirguis-Blake J, Hennessy KD, et al. Translating research into improved outcomes in comprehensive cancer control. Cancer Causes Control. 2005 Oct;16 Suppl 1:27-40. http://dx.doi.org/10.1007/s10552-005-0488-y; PMid:16208572

10. Butterfoss FD, Goodman RM, Wandersman A. Community coalitions for prevention and health promotion: factors predicting satisfaction, participation, and planning. Health Educ Q. 1996 Feb;23(1):65-79. http://dx.doi.org/10.1177/109019819602300105; PMid:8822402

11. Butterfoss FD, Webster JD, Morrow AL, et al. Immunization coalitions that work: training for public health professionals. J Public Health Manag Pract. 1998 Nov;4(6):79-87. http://dx.doi.org/10.1097/00124784-199811000-00012; PMid:10187081

12. Fawcett SB, Lewis RK, Paine-Andrews A, et al. Evaluating community coalitions for prevention of substance abuse: the case of Project Freedom. Health Educ Behav. 1997 Dec;24(6):812-28.; PMid:9408793

13. Mizrahi T, Rosenthal BB. Complexities of coalition building: leaders' successes, strategies, struggles, and solutions. Soc Work. 2001 Jan;46(1):63-78. http://dx.doi.org /10.1093/sw/46.1.63; PMid:11217495

14. Goodman RM, Wandersman A, Chinman M, et al. An ecological assessment of community-based interventions for prevention and health promotion: approaches to measuring community coalitions. Am J Community Psychol. 1996 Feb;24(1):33-61. http://dx.doi.org/10.1007/BF02511882; PMid:8712187

15. Cargo M, Mercer SL. The value and challenges of participatory research: strengthening its practice. Annu Rev Public Health. 2008;29:325-50. http://dx.doi.org/10.1146 /annurev.publhealth.29.091307.083824; PMid:18173388

16. Manafo E, Petermann L, Lobb R, et al. Research, practice, and policy partner- 
ships in pan-Canadian coalitions for cancer and chronic disease prevention. J Public Health Manag Pract. 2011 Nov-Dec;17(6):E1-E11. http://dx.doi.org/10.1097 /PHH.0b013e318215a4ae; PMid:21964372

17. Baquet CR. A model for bidirectional community-academic engagement (CAE): overview of partnered research, capacity enhancement, systems transformation, and public trust in research. J Health Care Poor Underserved. 2012 Nov;23(4):1806-24. http://dx.doi.org/10.1353/hpu.2012.0155; PMid:23698691

18. Mitchell R, Stevenson J, Florin P. A typology of prevention activities: applications to community coalitions. J Prim Prev. 1996 Jun;16(4):413-36. http://dx.doi.org/10.1007 /BF02411744; PMid:24254855

19. Mullins CD, Blatt L, Gbarayor CM, et al. Health disparities: a barrier to high-quality care. Am J Health Syst Pharm. 2005 Sep 15;62(18):1873-82. http://dx.doi.org/10.2146 /ajhp050064; PMid:16141106 PMCid:PMC3262677

20. Lawsin C, DuHamel K, Weiss A, et al. Colorectal cancer screening among low-income African Americans in East Harlem: a theoretical approach to understanding barriers and promoters to screening. J Urban Health. 2007 Jan;84(1):32-44. http://dx.doi.org /10.1007/s11524-006-9126-6; PMid:17186375 PMCid:PMC2078250

21. Shokar NK, Carlson CA, Weller SC. Factors associated with racial/ethnic differences in colorectal cancer screening. J Am Board Fam Med. 2008 Sep-Oct;21(5):414-26. http://dx.doi.org/10.3122/jabfm.2008.05.070266; PMid:18772296

22. Lemon SC, Zapka JG, Estabrook B, et al. Challenges to research in urban community health centers. Am J Public Health. 2006 Apr;96(4):626-8. Epub 2006 Jan 31. http:// dx.doi.org/10.2105/AJPH.2004.057976; PMid:16449595 PMCid:PMC1470532

23. Ayanian JZ, Zaslavsky AM, Guadagnoli E, et al. Patients' perceptions of quality of care for colorectal cancer by race, ethnicity, and language. J Clin Oncol. 2005 Sep 20;23(27):6576-86. Epub 2005 Aug 22. http://dx.doi.org/10.1200/JCO.2005.06.102; PMid:16116149

24. Lasser KE, Murillo J, Medlin E, et al. A multilevel intervention to promote colorectal cancer screening among community health center patients: results of a pilot study. BMC Fam Pract. 2009 May 29;10:37. http://dx.doi.org/10.1186/1471-2296-10-37; PMid:19480698 PMCid:PMC2694166

25. Cruz DA, Hager CL. Eliminating racial and ethnic health disparities: opportunities and challenges for the Commonwealth. Issue Brief (Mass Health Policy Forum). 2001 Feb 15;(11):1-26.

26. Gomez SL, Tan S, Keegan TH, et al. Disparities in mammographic screening for Asian women in California: a cross-sectional analysis to identify meaningful groups for targeted intervention. BMC Cancer. 2007 Oct 26;7:201. http://dx.doi.org/10.1186 /1471-2407-7-201; PMid:17961259 PMCid:PMC2198916

27. Green AR, Peters-Lewis A, Percac-Lima S, et al. Barriers to screening colonoscopy for low-income Latino and white patients in an urban community health center. J Gen Intern Med. 2008 Jun;23(6):834-40. http://dx.doi.org/10.1007/s11606-008-0572-6; PMid:18350339 PMCid:PMC2517890

28. Gwede CK, Menard JM, Martinez-Tyson D, et al. Strategies for assessing community challenges and strengths for cancer disparities participatory research and outreach. Health Promot Pract. 2010 Nov'11(6):876-87. Epub 2009 Jan 10.

29. Greene P, Mays G, Kim K, et al. Colorectal cancer screening in Arkansas: implications for cancer prevention in primary care. J Ark Med Soc. 2009 Sep;106(3):66-8.; PMid:19947018 
30. Yeary K, Flowers E, Ford G, et al. Development of a community-based participatory colorectal cancer screening intervention to address disparities, Arkansas, 2008-2009. Prev Chronic Dis. 2011 Mar;8(2):A47. Epub 2011 Feb 15.; PMid:21324261 PMCid:PMC3073440

31. Greene P, Mehta P, Yeary KH, et al. Using population data to reduce disparities in colorectal cancer screening, arkansas, 2006. Prev Chronic Dis. 2012;9:E138. http:// dx.doi.org/10.5888/pcd9.110256; PMid:22898236 PMCid:PMC3475514

32. Institute of Medicine. The future of the public's health in the 21st century. Washington, DC: Institute of Medicine, 2002.

33. Harrop JP, Nelson DE, Kuratani DG, et al. Translating cancer prevention and control research into the community setting: workforce implications. J Cancer Educ. 2012 May;27 Suppl 2:S157-S64. http://dx.doi.org/10.1007/s13187-012-0329-0; PMid:22362356

34. Preston MA. Reducing cancer disparities through community engagement in policy development: the role of cancer councils. Washington, DC: American Public Health Association, 2011. 